\title{
Heritability of metabolic response to the intravenous glucose tolerance test in German Holstein Friesian bulls
}

\author{
Laura Pieper, ${ }^{*} \dagger^{1}$ Rudolf Staufenbiel, ${ }^{*}$ Jana Christ, ${ }^{*}$ Lothar Panicke, $\ddagger^{2}$ Uwe Müller, $\S$ \\ and Gudrun A. Brockmann§ \\ ${ }^{*}$ Ruminant and Swine Clinic, and \\ †Institute for Veterinary Epidemiology and Biostatistics, Free University of Berlin, 14163 Berlin, Germany \\ łLeibniz Institute for Farm Animal Biology (FBN), 18196 Dummerstorf, Germany \\ §Albrecht Daniel Thaer-Institute for Agricultural and Horticultural Sciences, Animal Breeding Biology and Molecular Genetics, \\ Humboldt University of Berlin, 10115 Berlin, Germany
}

\section{ABSTRACT}

Selection for improved health and welfare in farm animals is of increasing interest worldwide. Peripartum energy balance is a key factor for pathogenesis of diseases in dairy cows. The intravenous glucose tolerance test (ivGTT) can be used to study the metabolic response to a glucose stimulus. The aim of this study was to estimate heritability of ivGTT traits in German Holstein bulls. A total of 541 Holstein bulls aged 7 to 17 mo from 2 breeding stations were subjected to the ivGTT. Serum glucose concentrations were measured at $0,7,14,21,28,35,42,49,56$, and 63 min relative to glucose infusion. The maximum increase in blood glucose concentration, glucose area equivalent, and blood glucose half-life period were calculated. Heritabilities were estimated using a univariate animal model including station-year-season and age as fixed effects, and animal additive genetic and residual as random effects. The estimated heritabilities were 0.19 for fasting glucose concentration, 0.43 for glucose area equivalent, 0.40 for glucose half-life period, 0.14 for the peak glucose concentration, and 0.12 for the maximum increase of blood glucose concentration. Correlations between ivGTT traits and breeding values for milk yield and composition were not found. The results indicate that heritability for response to glucose is high, which warrants further investigation of this trait for genetic improvement of metabolic disorders. Research is necessary to determine the target levels of ivGTT traits and potential associations between ivGTT traits in breeding bulls and periparturient diseases in their offspring. Key words: glucose tolerance test, breeding bull, heritability, glucose, metabolism

Received November 23, 2015.

Accepted May 10, 2016.

${ }^{1}$ Corresponding author: laura.pieper@fu-berlin.de

${ }^{2}$ Deceased.

\section{INTRODUCTION}

Interest in breeding dairy cows for health and longevity is increasing (Zwald et al., 2004; Reents and Rensing, 2009; Swalve, 2012; Jamrozik et al., 2016). To obtain genetic progress in these areas, it is necessary to identify new selection traits for the estimation of breeding values. Estimating breeding values based on producer-recorded health data has been difficult due to poor data quality, low disease incidence and heritability (Zwald et al., 2004; Jamrozik et al., 2016), and long generation interval. On the other hand, quantitatively measureable blood and milk metabolites have only low to moderate heritability (Table 1 ). However, traits should have medium to high heritability to be used effectively as additional selection criteria in breeding programs. Ideally, there should be genetically advantageous or no associations between a new test trait and breeding values for milk production and functional traits to allow for selection for metabolic health without negatively affecting genetic progress in other traits. Furthermore, it would be valuable to obtain information on the new trait from young breeding bulls rather than their offspring to allow quick availability of test results for breeding purposes.

Many diseases in dairy cows such as ketosis, displaced abomasum, retained placenta, metritis, and mastitis are associated with poor adaptation to changes in energy metabolism at the onset of lactation (Drackley et al., 2005). During early lactation, the majority of glucose is directed toward milk production. This is achieved by a decreased insulin release after a glucose stimulus and decreased insulin sensitivity in peripheral tissues (Hayirli, 2006). In the mammary gland, glucose is taken up mainly for lactose production by the insulin-independent glucose transporter GLUT1, which has a higher expression in early lactation than in the dry period (Zhao, 2014). The metabolic priority toward synthesis of lactose during the early lactation period is associated with a deficit of available energy for other body 
Table 1. Heritability estimates of blood glucose and ketone bodies in the literature

\begin{tabular}{lcrrll}
\hline Trait & $\mathrm{h}^{2}$ & $\mathrm{SE}$ & \multirow{2}{*}{ No. of animals } & Notes & Reference \\
\hline Glucose & 0.17 & 0.11 & 411 & Different breeds, male & Panicke et al., 2000 \\
Glucose & 0.21 & 0.15 & 192 & Holstein cows & Ahn et al., 2006 \\
Glucose & 0.15 & 0.07 & 1,003 & Danish Holstein, male & Hayhurst et al., 2007 \\
Glucose & 0.27 & 0.06 & 1,438 & Danish breeds, male & Hayhurst et al., 2007 \\
Glucose & 0.37 & 0.21 & 174 & Holstein heifers & Oikonomou et al., 2008 \\
Glucose & 0.23 & 0.11 & 496 & UK Holsteins, female & Hayhurst et al., 2009 \\
Glucose & 0.13 & 0.06 & 320 & UK Holsteins, female & Hayhurst et al., 2009 \\
Glucose & 0.20 & 0.10 & 256 & UK Holsteins, male & Hayhurst et al., 2009 2007 \\
Free fatty acids & 0.15 & 0.06 & 1,007 & Danish Holstein, male & Hayhurst et al., 2007 \\
Free fatty acids & 0.11 & 0.05 & 1,443 & Danish breeds, male & Oikonomou et al., 2008 \\
Free fatty acids & 0.29 & 0.20 & 142 & Holstein heifers & Hayhurst et al., 2009 \\
Free fatty acids & 0.25 & 0.13 & 496 & UK Holsteins, female & Hayhurst et al., 2009 \\
Free fatty acids & 0.09 & 0.05 & 320 & UK Holsteins, female & Hayhurst et al., 2009 \\
Free fatty acids & 0.12 & 0.06 & 256 & UK Holsteins, male & Oikonomou et al., 2008 \\
BHB & 0.25 & 0.18 & 175 & Holstein heifers & van der Drift et al., 2012 \\
BHB & 0.17 & 0.06 & 1,615 & Dutch cattle & Jamrozik et al., 2016 \\
BHB & 0.13 & 0.03 & 4,867 & Canadian Holstein, 1st lactation & Jamrozik et al., 2016 \\
BHB & 0.07 & 0.02 & 3,279 & Canadian Holstein, $>1$ 1st lactation & Tveit et al., 1992 \\
Plasma acetoacetate & 0.11 & 0.08 & 361 & Norwegian cattle &
\end{tabular}

functions and, therefore, increases the lipolysis in fat depots to overcome the energy deficit. Under conditions of starvation, ketogenesis is the predominant pathway (Kaneko et al., 1997). Consequently, strong relationships are present between glucose and lipid metabolism. Impaired glucose homeostasis might result in increased fat mobilization, ketogenesis, and related diseases.

A standardized method to assess the capacity for glucose homeostasis is the intravenous glucose tolerance test (ivGTT). Glucose tolerance is measured as the capacity of the body to maintain the normal blood glucose concentration after a glucose stimulus. For normal glucose clearance, the height and time point of the blood glucose peak after glucose administration and the time needed to reach the basal level are important. An animal has an impaired glucose tolerance if the peak is very high and the basal blood glucose level cannot be reached after 1 to $2 \mathrm{~h}$. Low glucose tolerance is a result of low insulin availability or function.

In cattle, the results of the ivGTT are strongly influenced by age, sex, housing, nutrition, stage of lactation, and milk yield (Burkert, 1998; Staufenbiel et al., 1999; Behn, 2008). To obtain reliable results and decrease the costs for the breeding program, it was suggested to conduct the ivGTT in breeding bulls (Behn, 2008). The ideal time for testing bulls is between 12 and 15 mo of age (Behn, 2008). Currently, no studies have investigated large populations of cattle that were subjected to the ivGTT under controlled conditions.

Therefore, the objectives of this study were (1) to estimate heritabilities of ivGTT traits and (2) to investigate correlations among ivGTT traits and breeding values for milk production traits in young German Holstein bulls kept under controlled conditions.

\section{MATERIALS AND METHODS}

\section{Animals and Housing}

The ivGTT was conducted on 541 German Holstein bulls that were born in 1993 and between 1998 and 2003. The bulls were between 199 and $518 \mathrm{~d}$ of age and $79 \%$ of the bulls were between 12 to 15 mo of age. They were kept in 2 German test stations for breeding bulls; $290(53.6 \%)$ and $251(46.4 \%)$ animals were tested on station 1 and station 2, respectively (Table 2). Bull calves at 2 to 4 mo of age were housed in the bull raising barns of the breeding stations after a quarantine of $28 \mathrm{~d}$. In station 1, bulls were kept in tie-stalls with headlocks on straw bedding. The feed was composed of $6 \mathrm{~kg}$ of hay and, additionally, different silages, depending on the season. In station 2, groups of 4 bulls each were kept on straw. The bulls were fed baled silage ad libitum. In both stations, supplementary grain was fed and water was available ad libitum through automatic water bowls.

A total of 1,153 animals were included in the relationship matrix. The bulls were offspring of 147 sires and 465 dams. Among the tested bulls, 45 (8.32\%) did not have brothers, 50 (9.24\%) had one half- or full-brother, and $446(82.44 \%)$ had 2 or more half- or full-brothers. Thirty-two bulls were full brothers, 7 were maternal half-brothers, 359 were paternal half-brothers, and 98 were paternal and maternal half-brothers.

On average, bulls had 582 daughters in Germany (range: 44 to 49,032). Pedigree information, EBV for milk, fat and protein yield, fat and protein percentage as well as relative breeding value for milk production traits and total merit index for all animals were obtained from the data center Vereinigte Informations- 
systeme Tierhaltung w.V. (vit, Verden, Germany). A detailed description of the current breeding values and breeding value estimation was provided by the Vereinigte Informationssysteme Tierhaltung (2015).

\section{Intravenous Glucose Tolerance Test}

Prior to the test, the bulls were fasted for 12 to 16 $\mathrm{h}$ after the last meal in the afternoon with water being available at all times. Body weight was measured by weighing with an electronic scale. An intravenous catheter was placed into a jugular vein, and a blood sample was taken for the determination of the fasting glucose concentration (g0) immediately before glucose injection. Thereafter, $1 \mathrm{~g}$ of glucose per $\mathrm{kg}$ of $\mathrm{BW}^{0.75}$ was infused over 1 to 3 min using a $40 \%$ glucose solution. Blood samples were taken at 7, 14, 21, 28, 35, 42, 49,56 , and $63 \mathrm{~min}$ after the glucose infusion to quantify change in glucose concentration. The blood samples were centrifuged within $2 \mathrm{~h}$ and serum was collected and stored at $-18^{\circ} \mathrm{C}$.

Serum glucose concentration was measured with an automatic photometer (Hitachi High-Technologies Europe GmbH, Mannheim, Germany) using the hexokinase test kit Gluco-Quant (Roche Diagnostics GmbH, Mannheim, Germany). Laboratory sensitivity of this method was at $0.11 \mathrm{mmol} / \mathrm{L}$. Fasting glucose concentration, peak glucose concentration (gmax) at 7 min after glucose infusion and glucose concentration at the remaining sampling times were determined. Maximum glucose increase $(\mathbf{d m a x})$, glucose half-life period (gHL), and glucose area equivalent (gA) were calculated (Figure 1). Glucose half-life period was calculated as modified by Kaneko et al. (1997) by regression of the natural logarithm of the glucose concentrations:

$$
\mathrm{gHL}=[\ln (2) / \mathrm{k}] \times 100(\min ),
$$

where $\mathrm{k}$ is the slope calculated using the method of the smallest sums of squares and is equivalent to the turnover rate $\mathrm{k}=[\ln (\mathrm{G} 14)-\ln (\mathrm{G} 42)] /(\mathrm{T} 42-\mathrm{T} 14) \times$

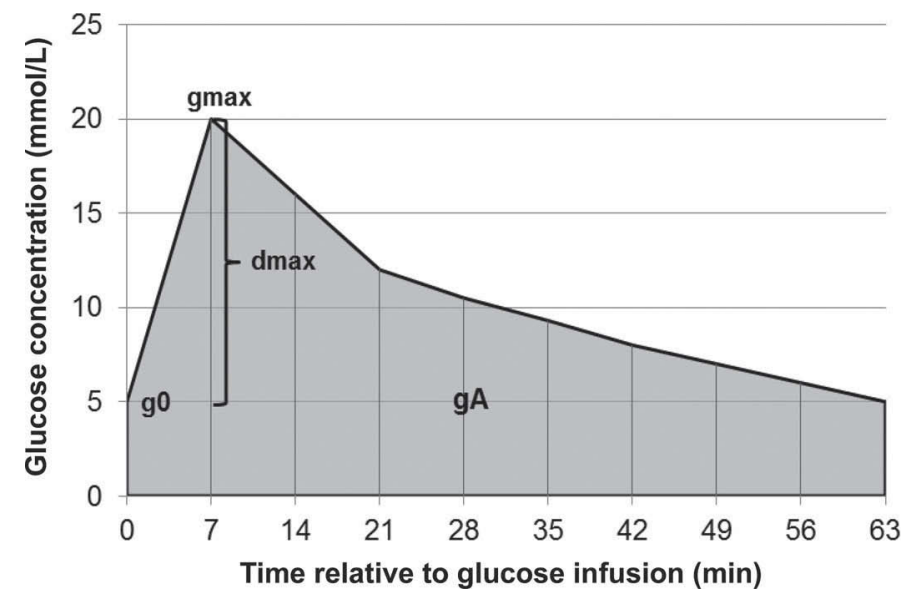

Figure 1. Schematic of change in blood glucose concentration including traits of the intravenous glucose tolerance test; g0 = fasting glucose concentration; $d \max =$ maximum glucose increase; gmax $=$ peak glucose concentration; gA $=$ (shaded area) glucose area equivalent.

100 (\% per min). G14 and G42 represent the glucose concentration at 14 and 42 min after glucose infusion, respectively; T42-T14 denotes the time interval between min 14 and 42.

The $\mathrm{gA}$ is an approximation for the area under the glucose curve. It is calculated by adding up the 9 glucose concentrations after infusion and does not have a unit.

A detailed description is provided in Staufenbiel et al. (1992), Burkert (1998), and Panicke et al. (2003).

\section{Statistical Analyses}

Breeding values and ivGTT traits were graphically assessed for normality with histograms and quantilequantile plots using the computer program $\mathrm{R}$ for Windows (version 2.12.2; R Development Core Team, Vienna, Austria). Breeding values were normally distributed and ivGTT traits were approximately normally distributed after logarithmic transformation (base e).

Table 2. Distribution of animals tested by birth year and breeding station

\begin{tabular}{lcccccc}
\hline $\begin{array}{l}\text { Year } \\
\text { of birth }\end{array}$ & Station 1 & Percentage & Station 2 & Percentage & $\begin{array}{c}\text { Total number } \\
\text { of bulls per year } \\
\text { in both stations }\end{array}$ & Percentage \\
\hline 1993 & 13 & 2.4 & 30 & 5.5 & 43 & 7.9 \\
1998 & 54 & 10.0 & 44 & 8.1 & 98 & 18.1 \\
1999 & 59 & 11.1 & 44 & 8.1 & 103 & 19.2 \\
2000 & 57 & 10.5 & 39 & 7.2 & 96 & 17.7 \\
2001 & 49 & 9.0 & 42 & 7.7 & 91 & 16.8 \\
2002 & 51 & 9.4 & 31 & 5.7 & 82 & 5.2 \\
2003 & 7 & 1.3 & 21 & 3.9 & 28 & 100 \\
Total & 290 & 53.6 & 251 & 46.4 & 541 & \\
\hline
\end{tabular}


All log-transformed ivGTT traits (outcome variables) were analyzed with univariate linear models that included station, birth year, season, station-yearseason, age in days, and age group as fixed effects using the MIXED procedure (method $=\mathrm{ML})$ in $\operatorname{SAS}(9.3$, SAS Institute Inc., Cary, NC). Model selection was performed using Akaike information criteria, with smaller values being favorable. Based on that, station-yearseason and age in days were chosen as fixed effects. The station-year-season effect consists of the season, year, and station and represents effects of feeding, station, and seasonal changes (e.g., temperature, light). The additive genetic variance component for animal and the error variance were calculated using an animal model in VCE 6.0 (Groeneveld et al., 2010). Using PEST 4.2.5 (Groeneveld et al., 1990), univariate models to estimate the animal effects were built with the following formula:

$$
\mathrm{y}_{\mathrm{ijk}}=\mu+\mathrm{SYS}_{\mathrm{i}}+\mathrm{Age}_{\mathrm{j}}+\text { Animal }_{\mathrm{k}}+\mathrm{e}_{\mathrm{ijk}},
$$

where $\mathrm{y}_{\mathrm{ijk}}$ is the log-transformed ivGTT trait value from the individual animal k, $\mu$ is the intercept, $\mathrm{SYS}_{\mathrm{i}}$ is the ith station-year-season effect, $\mathrm{Age}_{\mathrm{j}}$ is the $\mathrm{jth}$ age of the tested animal in days, Animal $_{\mathrm{k}}$ is the additive genetic effect in the kth animal, and $\mathrm{e}_{\mathrm{ijk}}$ is the random error. All log-transformed ivGTT traits were estimated with the same model. Heritability was defined as the proportion of the additive genetic variance $\left(\mathrm{V}_{\mathrm{A}}\right)$ and the phenotypic variance $\left(\mathrm{V}_{\mathrm{P}}\right)$ :

$$
\mathrm{h}^{2}=\mathrm{V}_{\mathrm{A}} / \mathrm{V}_{\mathrm{P}}
$$

Significance of heritability estimates was assessed using the 1-sample $t$-test (2-sided). Pearson correlation coefficients were used to evaluate the associations among breeding values and animal effects of the log-transformed ivGTT traits. A $P$-value $<0.05$ was considered significant.

\section{RESULTS}

Descriptive statistics for ivGTT traits for each station are shown in Table 3 . The mean g0 was $4.5 \mathrm{mmol} / \mathrm{L}$ $(\mathrm{SD}=0.5)$ for both stations. Glucose concentration increased on average $8.9 \mathrm{mmol} / \mathrm{L}(\mathrm{SD}=1.4)$ and the mean gmax was $13.3 \mathrm{mmol} / \mathrm{L}(\mathrm{SD}=1.4)$. The mean gHL was $49.1 \mathrm{~min}(\mathrm{SD}=13.6)$, ranging from 19.0 to $117.1 \mathrm{~min}$.

The greatest phenotypic and error variances were observed for log-transformed g0, gA, and gHL (Table 4). Furthermore, the log-transformed traits gA and gHL had the greatest additive genetic variances. For the log-transformed trait gHL, which characterizes the individual reaction to a glucose stimulus, heritability was estimated to be $\mathrm{h}^{2}=0.4(\mathrm{SE}=0.20 ; P=0.046)$. Heritability of gA (log-transformed) was $\mathrm{h}^{2}=0.43(\mathrm{SE}$ $=0.22 ; P=0.051)$. The estimated heritabilities for the log-transformed traits g0, gmax, and dmax were only small to moderate, ranging from $\mathrm{h}^{2}=0.12$ to $\mathrm{h}^{2}=0.19$ $(P>0.1)$.

The mean estimated breeding values for milk, fat, and protein yield were $246,7.9$, and $7.5 \mathrm{~kg}$, respectively (Table 5). The mean relative breeding values for milk production and mean total merit index were 97.7 and 97.0, respectively. The mean accuracy was above $94 \%$ for all traits except for total merit index with a mean accuracy of $88 \%$.

Correlations among breeding values and animal effects of the log-transformed ivGTT traits were very small, ranging from $\mathrm{r}=-0.06$ to $\mathrm{r}=0.07$ (Table 6). None of the correlation coefficients was statistically significant.

\section{DISCUSSION}

The present study reveals a high heritability of the ivGTT traits gA and gHL in adolescent German Holstein bulls. The gHL values were between 19 to 117 min, which is similar to values previously reported for normal cows (35 min) but lower than values reported for a spontaneously diabetic cow (182 min; Kaneko et al., 1997).

Currently, there is a great interest in the implementation of measures for resistance to metabolic and

Table 3. Descriptive statistics of the intravenous glucose tolerance

\begin{tabular}{|c|c|c|c|c|}
\hline Trait & Mean & SD & Minimum & Maximum \\
\hline \multicolumn{5}{|l|}{ Total $; \mathrm{n}=541$} \\
\hline g0 (mmol/L) & 4.5 & 0.5 & 2.6 & 6.4 \\
\hline gA & 36.3 & 7.4 & 13.6 & 67.1 \\
\hline gHL (min) & 49.1 & 13.6 & 19.0 & 117.1 \\
\hline $\mathrm{dmax}(\mathrm{mmol} / \mathrm{L})$ & 8.9 & 1.4 & 5.9 & 15.4 \\
\hline $\operatorname{gmax}(\mathrm{mmol} / \mathrm{L})$ & 13.3 & 1.4 & 10.6 & 20.0 \\
\hline \multicolumn{5}{|l|}{ Station $1 ; \mathrm{n}=290$} \\
\hline $\mathrm{g} 0(\mathrm{mmol} / \mathrm{L})$ & 4.3 & 0.5 & 2.6 & 6.4 \\
\hline gA & 38.3 & 7.3 & 15.3 & 67.1 \\
\hline gHL (min) & 48.0 & 13.2 & 24.3 & 116.7 \\
\hline $\operatorname{dmax}(\mathrm{mmol} / \mathrm{L})$ & 9.2 & 1.2 & 6.4 & 14.0 \\
\hline $\operatorname{gmax}(\mathrm{mmol} / \mathrm{L})$ & 13.4 & 1.3 & 11.0 & 18.4 \\
\hline \multicolumn{5}{|l|}{ Station $2 ; \mathrm{n}=251$} \\
\hline g0 (mmol/L) & 4.7 & 0.4 & 3.2 & 6.0 \\
\hline $\mathrm{gA}$ & 33.9 & 6.8 & 13.6 & 52.5 \\
\hline gHL (min) & 50.4 & 14.0 & 19.0 & 117.1 \\
\hline $\operatorname{dmax}(\mathrm{mmol} / \mathrm{L})$ & 8.5 & 1.6 & 5.9 & 15.4 \\
\hline $\operatorname{gmax}(\mathrm{mmol} / \mathrm{L})$ & 13.2 & 1.6 & 10.6 & 20.0 \\
\hline
\end{tabular}
test in 541 German Holstein bulls ${ }^{1}$

${ }^{1} 00$ fasting glucose concentration; $\mathrm{gA}=$ glucose area equivalent; $\mathrm{gHL}=$ glucose half-life period; $\mathrm{dmax}=$ maximum glucose increase over the fasting glucose concentration at $\mathrm{g} 0$; gmax $=$ peak glucose concentration. 
Table 4. Variance parameters and heritabilities of intravenous glucose tolerance test traits estimated from 541 adolescent bulls ${ }^{1}$

\begin{tabular}{lcccccc}
\hline $\begin{array}{l}\text { Trait } \\
\text { (log-transformed) }\end{array}$ & $\mathrm{V}_{\mathrm{A}}$ & $\mathrm{V}_{\mathrm{P}}$ & $\mathrm{V}_{\mathrm{E}}$ & $\mathrm{h}^{2}$ & $\mathrm{SE}$ & $P$-value $\left(\mathrm{h}^{2}\right)$ \\
\hline g0 & 0.005 & 0.027 & 0.022 & 0.19 & 0.14 & 0.175 \\
gA & 0.014 & 0.033 & 0.019 & 0.43 & 0.22 & 0.051 \\
gHL & 0.027 & 0.066 & 0.039 & 0.40 & 0.20 & 0.046 \\
gmax & 0.001 & 0.007 & 0.006 & 0.14 & 0.14 & 0.318 \\
dmax & 0.001 & 0.008 & 0.007 & 0.12 & 0.19 & 0.528 \\
\hline
\end{tabular}

${ }^{1} \mathrm{~g} 0$ = fasting glucose concentration; $\mathrm{gA}=$ glucose area equivalent; $\mathrm{gHL}=$ glucose half-life period; $\mathrm{dmax}=$ maximum glucose increase above g0; gmax = peak glucose concentration; $\mathrm{h}^{2}=$ heritability; $\mathrm{SE}=$ standard error for heritability estimates; $V_{A}=$ additive genetic variance; $V_{P}=$ phenotypic variance; $V_{E}=$ environmental variance.

other diseases in breeding programs for dairy cows, but heritabilities are usually low and not useful for breeding purposes (Jamrozik et al., 2016). One approach might be to search for a trait with high heritability on the level of metabolic regulation that has a logical relationship with the development of metabolic disorders. The ivGTT traits (especially gHL) likely fulfill these requirements and could be used to predict disease resistance. To date, few researchers have investigated the heritability of ivGTT traits. Panicke et al. (2000) subjected 411 bulls of different ages (129 to $2756 \mathrm{~d}$ ) to ivGTT and found heritabilities of $\mathrm{h}^{2}=0.17$ ( $\mathrm{SE}=$ $0.11)$ for $g 0, h^{2}=0.28(\mathrm{SE}=0.16)$ for $\operatorname{gmax}, \mathrm{h}^{2}=0.16$ $(\mathrm{SE}=0.10)$ for $\mathrm{gHL}$, and $\mathrm{h}^{2}=0.20(\mathrm{SE}=0.09)$ for gA. The bulls in the aforementioned study were likely in different physiological stages, ranging from calves with a physiologically high glucose tolerance to adult breeding bulls. Furthermore, the bulls were housed differently and belonged to different breeds and lines with limited family relationships, potentially increasing the standard errors for the estimates. Jaakson et al. (2010) showed that differences may be present in metabolic response to ivGTT between Estonian Holstein and Estonian Red. In the current study, heritability estimates for all ivGTT traits were higher, likely due to the stronger relationship structures and similar ages of the animals. Heritability estimates in the current study were also higher than estimates for metabolic traits associated with negative energy balance in dairy cows (van der Drift et al., 2012; Jamrozik et al., 2016). The heritability estimate for g0 of $\mathrm{h}^{2}=0.19$ ( $\mathrm{SE}=$ 0.14) was similar to estimates in male Holstein Friesian calves $\left(\mathrm{h}^{2}=0.2, \mathrm{SE}=0.1\right.$; Hayhurst et al., 2009) and in male Danish Holstein calves $\left(\mathrm{h}^{2}=0.15, \mathrm{SE}=0.07\right.$; Hayhurst et al., 2007).

In the current study, some of the bulls were older or younger than the target age range of 12 to 15 mo. Furthermore, the sample size was small, potentially resulting in increased standard errors and, therefore, reduced precision in heritability estimates. However, this is one of the first studies providing heritability estimates for these traits. Additional studies with larger sample sizes are necessary to confirm our results under more standardized conditions.

Correlations among animal effects of ivGTT traits and breeding values for milk yield were not determined in this study. This is in contrast to a study by Panicke et al. (2000), where highly negative correlations among gA and gHL and breeding values for milk, fat, and protein yield and the relative breeding value for milk yield were observed. However, these negative associations were only present in twenty-eight 3 -yr-old animals and correlations were smaller and not significant in younger animals. Similar to the present study, Hayhurst et al. (2009) did not find correlations among breeding values for production traits and glucose concentration in Hol-

Table 5. Breeding values and accuracy of 541 bulls

\begin{tabular}{|c|c|c|c|c|c|c|}
\hline Breeding value & \multicolumn{4}{|c|}{ Breeding value } & \multicolumn{2}{|c|}{ Accuracy $^{1}$} \\
\hline Milk yield (kg) & 246.8 & 626.4 & $-1,721.0$ & $2,092.0$ & 94.2 & 2.0 \\
\hline Fat percent (\%) & 0.0 & 0.3 & -0.8 & 1.2 & 94.2 & 2.0 \\
\hline Protein yield (kg) & 7.5 & 18.8 & -42.9 & 54.8 & 94.2 & 2.0 \\
\hline Protein percent (\%) & 0.0 & 0.1 & -0.4 & 0.6 & 94.2 & 2.0 \\
\hline
\end{tabular}

${ }^{1}$ Accuracy of the breeding value estimates. 
Table 6. Correlations (Pearson's r) among breeding values and animal effects for intravenous glucose tolerance test traits in 541 adolescent breeding bulls ${ }^{1}$

\begin{tabular}{|c|c|c|c|c|c|c|c|c|c|c|}
\hline Breeding value & \multicolumn{2}{|c|}{$\mathrm{AE} g 0$} & \multicolumn{2}{|c|}{$\mathrm{AE} g \mathrm{~A}$} & \multicolumn{2}{|c|}{ AE gHL } & \multicolumn{2}{|c|}{$\mathrm{AE} \mathrm{dmax}$} & \multicolumn{2}{|c|}{ AE gmax } \\
\hline Milk yield $(\mathrm{kg})$ & -0.06 & 0.16 & 0.00 & 0.97 & -0.05 & 0.24 & -0.02 & 0.63 & -0.04 & 0.31 \\
\hline Fat percent (\%) & 0.07 & 0.09 & 0.02 & 0.56 & 0.02 & 0.70 & 0.04 & 0.41 & 0.06 & 0.14 \\
\hline Protein yield (kg) & -0.05 & 0.29 & 0.02 & 0.58 & -0.04 & 0.35 & -0.02 & 0.70 & -0.03 & 0.45 \\
\hline Protein percent (\%) & 0.05 & 0.28 & 0.05 & 0.29 & 0.03 & 0.49 & 0.02 & 0.66 & 0.04 & 0.39 \\
\hline Total merit index & -0.03 & 0.52 & 0.06 & 0.18 & -0.01 & 0.73 & 0.01 & 0.90 & -0.01 & 0.87 \\
\hline
\end{tabular}

${ }^{1} \mathrm{AE}=$ animal effects of log-transformed glucose tolerance test trait; $\mathrm{g} 0=$ fasting glucose concentration; gA $=$ glucose area equivalent; gHL $=$ glucose half-life period; $\mathrm{dmax}=$ maximum glucose increase over the fasting glucose concentration at $\mathrm{g} 0$; gmax $=$ peak glucose concentration.

stein-Friesian calves. This indicates that animal effects of ivGTT traits obtained in adolescent bulls are not associated with breeding values for milk production and selection for a desired level of ivGTT traits might be done without affecting genetic progress in milk yield. Besides glucose homeostasis, there may be many other biological functions (e.g., feed intake, feed conversion) with different genetic factors that have a greater influence on milk production traits. For research purposes, we also suggest performing ivGTT in cows to better directly link glucose homeostasis and milk production. In dairy cows, glucose homeostasis might be affected by hormonal influences and lactation demands. One might speculate that the relationship between glucose homeostasis and milk production could be different in dairy cows and breeding bulls.

Metabolic traits and metabolic health are not routinely assessed in Holstein breeding programs. Breeding for metabolic resistance could help to reduce the incidence of metabolic disorders and improve animal health and welfare. As a consequence of negative energy balance in dairy cows, ketosis is one of the most common metabolic disorders around parturition (Kelton et al., 1998). The interpretation of the ivGTT traits directly relates to glucose and energy metabolism. A reduced glucose tolerance (long half-life period or large area equivalent) is a result of low insulin release or impaired insulin sensitivity of the cells. Insulin-sensitive tissues (muscle or adipose tissue) take up glucose from the blood stream. Other tissues, such as the mammary gland, do not depend on insulin for glucose uptake and can use glucose independently of insulin (Kaneko et al., 1997). Consequently, reduced glucose tolerance leads to higher blood glucose concentration, and hence, will favor milk production, whereas the energy supply for muscle and adipose tissues is impaired. Thus, fat mobilization is increased to compensate for the energy deficit. Therefore, the test is very valuable in assessing the individual metabolic capacity. However, the
ivGTT in dairy cows in the early postpartum period is highly influenced by DIM and milk yield and has only low repeatability (Behn, 2008). Furthermore, the test is very time consuming and variable environmental conditions can greatly influence the test results (Behn, 2008). Therefore, it would be most efficient to test for metabolic resistance in young sires under controlled conditions before their use in the breeding program. This would also make relevant breeding information available long before the offspring come in lactation (Panicke et al., 2001). To reduce the cost and the time required to conduct the test, genetic markers that are associated with ivGTT traits could be established in the future. It is necessary to collect the ivGTT data on bulls as in-depth phenotypes until the relationship between the genes and the specific response to ivGTT will be reliably detected. Although the costs are high for testing the animals using the ivGTT, most bulls are genotyped so that the association analysis is feasible. Likely, the genetic marker that determines the phenotype rather than the ivGTT will be used to characterize an animal for its capacity to maintain glucose homeostasis in the future.

Whereas the current study showed that ivGTT traits are heritable, associations with breeding values for milk production traits were not detected. The relationships between ivGTT traits in breeding bulls and health, reproduction, and culling rates in their offspring require further elucidation. In addition, it might be useful to further define the target range for ivGTT traits in adolescent breeding bulls as an asset for current breeding programs.

\section{CONCLUSIONS}

Due to their high heritability and lack of association with breeding values for milk production, the ivGTT traits glucose half-life period and glucose area equivalent could be included in selection strategies. Further 
research is necessary to establish the desired level of ivGTT traits and to study the relationship between those traits in breeding bulls and disease incidences and culling rates of their offspring.

\section{ACKNOWLEDGMENTS}

The authors thank the 2 participating breeding companies for their help and financial support for this project. We express our gratitude to Bernd Adler and Robert Dittman from RBB Rinderproduktion BerlinBrandenburg GmbH [Groß Kreutz (Havel), Germany] and Heiko Güldenpfennig and Claudia Wesenauer from RinderAllianz GmbH (Woldegk, Germany). This paper is dedicated to the memory of Lothar Panicke, who died in January 2012.

\section{REFERENCES}

Ahn, B. S., B. S. Jeon, E. G. Kwon, M. Ajmal Khan, H. S. Kim, J C. Ju, and N. S. Kim. 2006. Estimation of genetic parameters for daily milk yield, somatic cell score, milk urea nitrogen, blood glucose and immunoglobulin in Holsteins. Asian-australas. J. Anim. Sci. 19:1252-1256.

Behn, H. 2008. Examinations to detect the influence of methodical factors and animal individual factors on the results of the intravenous glucose tolerance test with female and male young dairy cattle and first lactating dairy cows [in German with English abstract]. Doctoral dissertation, Ruminant and Swine Clinic, Free University of Berlin, Germany.

Burkert, O. 1998. Investigations about the intravenous and modified glucose tolerance test in breeding bulls [in German with English abstract]. Doctoral dissertation, Ruminant and Swine Clinic, Free University of Berlin, Germany.

Drackley, J. K., H. M. Dann, G. N. Douglas, N. A. Janovick Guretzky, N. B. Litherland, J. P. Underwood, and J. J. Loor. 2005. Physiological and pathological adaptations in dairy cows that may increase susceptibility to periparturient diseases and disorders. Ital. J. Anim. Sci. 4:323-344.

Groeneveld, E., M. Kovac, and N. Mielenz. 2010. VCE User's Guide and Reference Manual. Version 6.0. Department of Animal Science. University of Illinois, Urbana.

Groeneveld, E., M. Kovac, and T. Wang. 1990. PEST, a general purpose BLUP package for multivariate prediction and estimation. Proc. 4th World Congr. Genet. Applied Livest. Prod. 13:488.

Hayhurst, C., A. P. F. Flint, P. Løvendahl, J. A. Woolliams, and M. D. Royal. 2009. Genetic variation of metabolite and hormone concentration in UK Holstein-Friesian calves and the genetic relationship with economically important traits. J. Dairy Sci. 92:4001-4007.

Hayhurst, C., M. K. Sørensen, M. D. Royal, and P. Løvendahl. 2007. Metabolic regulation in Danish bull calves and the relationship to the fertility of their female offspring. J. Dairy Sci. 90:3909-3916.

Hayirli, A. 2006. The role of exogenous insulin in the complex of hepatic lipidosis and ketosis associated with insulin resistance phenomenon in postpartum dairy cattle. Vet. Res. Commun. 30:749-774.

Jaakson, H., K. Ling, J. Samarütel, A. Ilves, T. Kaart, and O. Kärt. 2010. Field trial on glucose-induced insulin and metabolite responses in Estonian Holstein and Estonian Red dairy cows in two herds. Acta Vet. Scand. 52:4.
Jamrozik, J., A. Koeck, G. J. Kistemaker, and F. Miglior. 2016. Multiple-trait estimates of genetic parameters for metabolic disease traits, fertility disorders, and their predictors in Canadian Holsteins. J. Dairy Sci. 99:1990-1998.

Kaneko, J. J., J. W. Harvey, and M. L. Bruss. 1997. Appendix VIII: Blood Analyte Reference Values in Large Animals. Pages 885-905 in Clinical Biochemistry of Domestic Animals. J. J. Kaneko, J. W. Harvey, and M. L. Bruss, ed. Academic Press, San Diego, CA.

Kelton, D. F., K. D. Lissemore, and R. E. Martin. 1998. Recommendations for recording and calculating the incidence of selected clinical diseases of dairy cattle. J. Dairy Sci. 81:2502-2509.

Oikonomou, G., G. E. Valergakis, G. Arsenos, N. Roubies, and G. Banos. 2008. Genetic profile of body energy and blood metabolic traits across lactation in primiparous Holstein cows. J. Dairy Sci. 91:2814-2822.

Panicke, L., E. Fischer, B. Fischer, and R. Staufenbiel. 2003. Level estimation of metabolic parameters in the glucose tolerance test (GTT) of young bulls. Arch. Tierz. Dummerstorf. 46:167-176. (in German with English abstract).

Panicke, L., E. Fischer, and R. Staufenbiel. 2001. Variation and suitability of physiological indicators of the glucose tolerance test for the indirectly evaluation of young bulls. Arch Tierz. 44:381-394. (in German with English abstract).

Panicke, L., R. Staufenbiel, O. Burkert, E. Fischer, and F. Reinhardt. 2000. Relationships between parameters of the glucose tolerance test by young sires and estimated their breeding values. Arch Tierz. 43:231-239. (in German with English abstract).

Reents, R., and S. Rensing. 2009. Breeding goals for dairy breeds national and international. Zuchtungskunde 81:397-405. (in German with English abstract).

Staufenbiel, R., U. Reinicke, and L. Panicke. 1999. Investigations into glucose tolerance test in cattle. 1. Relations to stage of lactation and milk yield. Arch. Tierz. 42:45-56. (in German with English abstract).

Staufenbiel, R., U. Rischk, B. Schumacher, and W. Becker. 1992. Estimation of insulin and glucose regulation in the dairy cow using daily profiles, simple and modified glucose tolerance test. Dtsch. Tierarztl. Wochenschr. 99:69-75.

Swalve, H. H. 2012. Current status of genetic improvement of health and functionality in livestock. Zuchtungskunde 84:32-38. (in German with English abstract).

Tveit, B., F. Lingaas, M. Svendsen, and Ø. V. Sjaastad. 1992. Etiology of acetonemia in Norwegian cattle. 1. Effect of ketogenic silage, season, energy level, and genetic factors. J. Dairy Sci. 75:24212432.

van der Drift, S. G. A., K. J. E. van Hulzen, T. G. Teweldemedhn, R. Jorritsma, M. Nielen, and H. C. M. Heuven. 2012. Genetic and nongenetic variation in plasma and milk $\beta$-hydroxybutyrate and milk acetone concentrations of early-lactation dairy cows. J. Dairy Sci. 95:6781-6787.

Vereinigte Informationssysteme Tierhaltung (vit). 2015. Estimation of breeding values for milk production traits, somatic cell score, conformation, productive life and reproduction traits in German dairy cattle. Accessed Mar. 11, 2015. http://www.vit.de/fileadmin/ user_upload/vit-fuers-rind/zuchtwertschaetzung/milchrinder-zwsonline/Zws_Bes_eng.pdf.

Zhao, F.-Q. 2014. Biology of glucose transport in the mammary gland. J. Mammary Gland Biol. Neoplasia 19:3-17.

Zwald, N. R., K. A. Weigel, Y. M. Chang, R. D. Welper, and J. S. Clay. 2004. Genetic selection for health traits using producerrecorded data. I. Incidence rates, heritability estimates, and sire breeding values. J. Dairy Sci. 87:4287-4294. 